\title{
O fechamento de escolas do campo no Brasil: da totalidade social a materialização das diretrizes neoliberais
}

The closing of field schools in Brazil: from social totality to the materialization of neoliberal guidelines

Vanessa Costa dos Santos Fátima Moraes Garcia

Resumo: A escola/educação do campo deve ser destinada ao processo formativo pautado na construção de uma educação para todos os sujeitos e não somente a favor de uma classe. Com base nessa concepção, este texto apresenta resultados de uma pesquisa de mestrado e tem por objetivo revelar e compreender criticamente a política de fechamento de escolas do campo no Brasil, por meio de um processo histórico entre conquistas e retrocessos de políticas públicas para/na Educação do Campo. O ordenamento metodológico da pesquisa foi organizado por meio da abordagem qualitativa, com orientação no método do Materialismo Histórico Dialético, em que leis, resoluções, decretos, dados publicados em sites e órgãos oficiais sobre a educação do campo e o fechamento de escolas do campo no Brasil foram analisados e sistematizados. Concluímos que o fechamento de escolas do campo está baseado em um projeto de sociedade da e para a classe dominante, em que o Estado é cumplice por meio de seus arranjos políticos. Pelo oposto disto, defendemos uma escola do campo pautada na relação harmoniosa e justa com Terra como lugar de conhecimento, produção e sociabilidade humana.

Palavras-chave: Fechamento de escolas do campo. Políticas neoliberais. Educação do Campo.

Abstract: The school / field education must be destined to the formative process based on the construction of an education for all subjects and not only in favor of a class. Based on this conception, this text presents the results of a master's research and aims to reveal and critically understand the policy of closing rural schools in Brazil, through a historical process between achievements and setbacks of public policies for / in Field Education . The methodological ordering of the research was organized through the qualitative approach, with guidance in the method of Dialectical Historical Materialism, in which laws, resolutions, decrees, data published on websites and official institutions on rural education and the closing of rural schools in the country Brazil were analyzed and systematized. We conclude that the closure of schools in the countryside is based on a project of society by and for the ruling class, in which the State is complicit through its political arrangements. On the contrary, we defend a rural school based on a harmonious and fair relationship with Earth as a place of knowledge, production and human sociability.

Keywords: Closing of field schools. Neoliberal policies. Field Education.

\section{Introdução}

A classe trabalhadora do campo historicamente tem sido uma contraposição aos ideais apregoados pelo ideário neoliberal capitalista, assim o 
campo como um lugar de vida é também um espaço de resistência no enfrentamento ao capital. Contra essa oposição vem sendo destruídas as comunidades rurais, através de processos que impossibilitam a permanência de famílias no campo, a exemplo do fechamento de escolas do campo, que está baseado em um projeto de sociedade para a classe dominante.

Historicamente governos, empresas e negócios pautados na ordem 'neo'liberal tentam, a todo o momento impor um conjunto de propostas, projetos, programas e medidas educacionais - e em diversos outros setores - que expropriam os trabalhadores das formas de reprodução de sua existência. Dessa forma, a luta pelo acesso à educação e a terra como forma de resistência camponesa à inserção e expansão do capitalismo e das políticas neoliberais no campo é necessária e justa.

Assim, consideramos relevante pensar sobre algumas questões: Ao longo do tempo histórico houve conquistas de políticas públicas a favor da educação do campo? Se houve, porque continuamente "ações legais" de Estado permitem o fechamento de escolas do campo? Quais são as políticas públicas que contribui para o fechamento de escolas do campo?

A escola/educação do campo deve ser destinada ao processo formativo pautado na construção de uma educação transformadora, no intuito de ocasionar a ruptura do capital. Dentro dessa lógica, a pesquisa foi realizada, por meio da abordagem qualitativa, com orientação no método do Materialismo Histórico Dialético, pois compreendemos que fenômenos (coisas, elementos, fatores, etc.) não podem ser considerados fora de um contexto histórico, social, político, cultural e econômico, e outros, que tem origem na construção das relações humanas.

Para o ordenamento metodológico da pesquisa, nos reportaremos aqui ao seguinte objetivo: Revelar a política de fechamento de escolas do campo no Brasil, por meio de um processo histórico entre conquistas e retrocessos de políticas públicas para/na Educação do Campo.

Nesse contexto, fez-se necessário a análise de leis, resoluções e decretos sobre a educação do campo, também foram analisados dados publicados em sites e órgãos oficiais, como por exemplo: Instituto Brasileiro de Geografia e 
Estatística - IBGE, Censo escolar do Instituto Nacional de Estudos e Pesquisas Educacionais Anísio Teixeira - Inep.

Este trabalho se volta para a exposição de fatores concretos da realidade que faz parte do contexto da Educação do Campo e das políticas públicas. Para tal partimos de pressupostos teóricos, especialmente sustentados em conceitos e argumentos necessários para o aprofundamento dessa temática. Ao levar em consideração o objetivo, o presente estudo contribui para o aprofundamento da reflexão, debate e proposições para a Educação do Campo, identificando limites, problemáticas e ações contrárias às imposições desse modelo de produção capitalista neoliberal.

Verifica-se a necessidade de uma nova organização social com base numa nova consciência de ser humano, pois estamos constatando que não adianta medidas paliativas e superficiais na educação formal, se não houver a construção de uma nova organização educacional que efetivamente tome em si, em suas diferentes dimensões, a reconstrução do sujeito em seus aspectos singulares e universais - em sua integralidade. Defendemos que a educação seja um dos pilares, dentro do conjunto da integralidade do ser humano, como ponto de partida para uma nova consciência, para novas e equilibradas formas de sociabilidade.

\section{Políticas Públicas para a Educação do Campo: entre conquistas e retrocessos}

Lutar pela educação do campo e pelas escolas do campo implica pensar os objetivos subjacentes à classe trabalhadora, requer pensar na concepção de campo e de educação, exige pensar em um novo modo de produção para a sociedade e pressupõe pensar no público, na coletividade, no conteúdo da política, e não nos interesses imediatos de um determinado grupo.

Dentro das contradições da luta de classe na sociedade capitalista, as políticas públicas e em especial as educacionais apresentam-se como uma forma de legitimar a manutenção do poder da classe burguesa. E o Estado age como administrador dessas contradições sendo influenciado por diversas instâncias internacionais e nacionais que financiam a educação e direciona-a conforme seus interesses. A lógica de manutenção do poder está presente no 
Brasil desde o governo monárquico (1822-1889) até o republicano, pelo histórico das Constituições Federais do Brasil: as de 1824, 1891, 1934, 1937, 1946, 1967 e a vigente de 1988, assim como também no histórico de implementação de programas, projetos e leis, a exemplo da Lei de Diretrizes e Bases da Educação Nacional (LDB) de 1961, 1971, (em pleno regime militar) e a vigente, de 1996. Entretanto, entendemos que enquanto um espaço de contradição e da luta de classe, o Estado pode dar origem a programas e políticas que possibilitam a garantia de direitos e melhorias nas condições de vida da classe trabalhadora.

Apesar da força da classe dominante, as políticas públicas são também avanços positivos, ainda que a sua existência seja somente resultados das pressões sociais. Esses aspectos positivos se dão no campo da legitimidade de direitos individuais, e principalmente, coletivos. Por exemplo, a educação do campo só veio se colocar na agenda oficial dos governos através das políticas públicas sociais. Os marcos legais que normatizam o direito ao conhecimento científico e tecnológico e a escola do campo se apresentam como novas alternativas em direção ao não silenciamento diante de problemas e rótulos pejorativos em relação a população do campo.

As modificações nas práticas jurídicas e políticas do constitucionalismo brasileiro permitiu avanços em áreas como saúde (com a implementação do Sistema Único de Saúde - SUS), leis trabalhistas, direito à educação em todos os níveis de ensino, sendo esse um direito de todos e dever do Estado, garantido na Constituição de 1988. Mesmo com contradições em relação ao dever da família e a preparação para a chamada "cidadania", enquanto preparação para o trabalho assalariado, a constituição não deixou de ser um grande avanço em relação ao direito social e educacional. O direito a educação foi reafirmado pelo Estatuto da Criança e do Adolescente de 1990 (Art. 53 da Lei nº 8.090) e pela LDB (Lei n 9394/96).

A LDB (Lei n 9394/96) permitiu subir alguns degraus na legitimidade e institucionalidade à educação do campo, ao delinear em seu Art. 28 os primeiros caminhos da obrigatoriedade da oferta de educação básica para a população que vive no campo, afirmando a necessidade de adequações às peculiaridades de cada região, especialmente no que diz respeito aos conteúdos curriculares, 
ao trabalho no meio rural, metodologias, calendário escolar adequado às fases do ciclo agrícola e às condições climáticas de cada espaço geográfico rural.

As diretrizes operacionais para a educação básica nas escolas do campo, aprovadas pelo Ministério da Educação (MEC), pelo Conselho Nacional de Educação (CNE), e pela Câmara de Educação Básica (CEB), definidas nas resoluções (Resolução CNE/CEB n 01, de 03 de abril de 2002; Resolução $n^{\circ}$ 02, de 28 de abril de 2008; Resolução $n^{\circ}$ 5, de 22 de junho de 2012) possibilitaram a legalidade do direito a educação do campo, ao estabelecerem diretrizes curriculares nacionais para a educação escolar indígena na educação básica, ao definirem normas e princípios que devem reger as políticas públicas de atendimento ao meio rural, por isso são importantes conquistas que contrariam o ideário neoliberal de empresariamento da educação, ao valorizar o campo como um lugar de conhecimento, cultura e trabalho para a Vida.

A Resolução CNE/CEB n. 01/2002 foi uma conquista muito importante dos movimentos sociais e lideranças que reivindicavam uma educação do campo, uma vez que definiu a identidade da escola do campo, esclarecendo que a escola não se limita a sua localização geográfica. Definiu em seu Art. $7^{\circ}$ a responsabilidade dos sistemas de ensino, quanto a regulamentação de estratégias específicas de atendimento escolar do campo.

A Resolução $n^{\circ}$ 02, de 28 de abril de 2008 em seu Art. $1^{\circ}$ afirma que a Educação Básica do Campo compreende a Educação Infantil, Ensino Fundamental, Ensino Médio e Educação Profissional Técnica de nível médio integrada com o Ensino Médio e destina-se ao atendimento das populações do campo. Em seu Art. $3^{\circ}$ afirma que a "Educação Infantil e os anos iniciais do Ensino Fundamental serão sempre oferecidos nas próprias comunidades rurais, evitando-se os processos de nucleação de escolas e de deslocamento das crianças". (BRASIL, 2008). Algo muito importante em relação ao não fechamento de escolas do campo, pois afirma que o deslocamento das crianças deve efetivar-se somente em caso de extrema necessidade, uma vez que a prioridade do ensino deve ser nas escolas localizadas próximas as comunidades. Lembramos também que o Estatuto da Criança e do Adolescente (Lei 8069/90), 
no Art. 53, inciso $V$, determina que a criança e o adolescente têm direito à educação e o acesso à escola pública e gratuita próxima de sua residência.

A Resolução $n^{\circ} 5$, de 22 de junho de 2012, define as diretrizes curriculares nacionais para a educação escolar indígena na educação básica. No Art. $3^{\circ}$ da referida resolução traz os objetivos, no qual ratifica a necessidade de recuperação de memórias históricas, a reafirmação de identidades étnicas, a valorização de línguas e ciências etc. da população indígena. O Art. $4^{\circ}$ traz os elementos básicos para a organização, a estrutura e o funcionamento das escolas indígenas, no qual enfatiza a centralidade do território, salientando a importância da localização das escolas em território (terras) habitadas por comunidades indígenas.

Outra conquista da luta social contra as disparidades vividas pelas escolas do campo foi a Lei $\mathrm{n}^{\circ} 12.960$, de 27 de março de 2014, sancionada pela ex. Presidente Dilma Rousseff no qual alterou o Art. 28 da LDB n 9394/96 com o acréscimo do parágrafo único, estabelecendo que para o fechamento das escolas do campo é preciso ter o consentimento da comunidade e um diagnóstico precedido pelo respectivo sistema de ensino e o consentimento de órgãos normativos, a exemplo do Conselho Municipal de educação.

A lei 12.960/2014 é um marco para a classe trabalhadora do campo e para as lideranças sociais, pois foi por meio de embates e de reivindicações que o governo aprovou a lei, mas salientamos que entre a teoria e a prática há ainda um caminho muito grande a percorrer. Todos esses marcos legais infelizmente ainda não respondem à totalidade dos problemas e necessidades dos sujeitos do campo.

No conteúdo das legislações citadas a cima, diversas questões são abordadas, entre elas, incluem-se o reconhecimento do direito à educação, e o reconhecimento da responsabilidade dos órgãos públicos federais, estaduais e municipais para com a oferta da educação do campo nas comunidades rurais. Essas premissas faz nos perguntar se de fato a obrigatoriedade garante na prática a efetivação da lei. Faz nos questionar: quantas escolas na contemporaneidade têm materiais e livros didáticos que dialogam com o 
contexto local? Existem equipamentos, laboratórios, bibliotecas e brinquedotecas nos espaços de formação escolar do campo?

Se o governo brasileiro realmente proporcionasse condições para as escolas do campo produzissem seus próprios alimentos orgânicos, com profissionais qualificados para atuar na educação, com transporte escolar seguro disponível para transportar as crianças, assim se fosse necessário, para comunidades rurais vizinhas, com o deslocamento intracampo, não estaríamos discutindo a determinação das políticas neoliberais no processo de fechamento das escolas do campo. Seria inocência pensarmos que dentro da sociedade capitalista as conquistas legais em relação à educação do campo garantiria de fato a sua implementação.

\section{A política de nucleação e do transporte escolar}

Na contemporaneidade, para os capitalistas o campo é entendido como uma indústria do agronegócio, assim o esvaziamento do campo faz parte das estratégias de manutenção dessa lógica. As ações neoliberais que contribuem para tal objetivo giram em torno do abandono, precarização e fechamento de escolas do campo, assim os governantes efetivam políticas que viabilizam tais estratégias, a exemplo da manutenção da estrutura agrária, redução de custos econômicos na área da educação, saúde, cultura, serviços sociais, política de nucleação de escolas e o transporte escolar que beneficia o setor automobilístico.

O processo de nucleação de escolas do campo, segundo o Parecer CEB/23/2007, teve início no Brasil nas décadas de 1970 e 1980 e foram ampliadas em decorrência da LDB de 1996 e da criação do Fundo de Manutenção e Desenvolvimento do Ensino Fundamental e de Valorização do Magistério (FUNDEF), o que resulta em uma acentuada municipalização no Ensino Fundamental. A implementação de escolas nucleadas, que começou nos Estados do Sul e do Sudeste do Brasil, segundo o parecer, seguiu o modelo norte-americano, "consistia em reunir várias escolas ou salas ditas 'isoladas', que foram fechadas ou desativadas, agrupando-as em uma única escola nos distritos ou comunidades que reunissem maior número de pequenas 
comunidades em seu entorno" (CNE/CEB, $n^{\circ}$ 23/2007, p. 5). O parecer CNE/CEB $n^{\circ}$ 23/2007 homologado pelo Parecer CNE/CEB $n^{\circ}$ 3/2008 pelo Ministério da Educação nos esclarece que as principais justificações alegadas para a nucleação são: "baixa densidade populacional determinando a sala multisseriada e a unidocência; facilitação da coordenação pedagógica; racionalização da gestão e dos serviços escolares; e melhoria da qualidade da aprendizagem" (CNE/CEB n 3/2008, p. 6). Entretanto, os processos históricos revela-nos que na prática a proposta de nucleação significa o fechamento de escolas do campo, pois ao nuclear uma determinada escola, necessariamente há a "paralização" de outras escolas, que na realidade significa o seu fechamento.

A obrigatoriedade do oferecimento do transporte escolar enquanto assistência educacional advinda de recursos do Fundo de Manutenção e Desenvolvimento do Ensino Fundamental e de Valorização do Magistério (FUNDEF), instituído pela Emenda Constitucional n. ${ }^{\circ}$ 14, de setembro de 1996 é datado em $1^{\circ}$ de janeiro de 1998 com a implantação nacionalmente do FUNDEF, o qual passa a vigorar a nova sistemática de redistribuição dos recursos destinados ao Ensino Fundamental. A partir de 1998 com a lei do FUNDEF, passa a priorizar recursos para ser destinado ao transporte escolar, com a aquisição de veículos escolares para o transporte de estudantes do ensino fundamental no meio rural, bem como a manutenção desses veículos.

O transporte escolar, nesse período, ampliou a oportunidade de educação escolar às populações do meio rural, tendo em vista que no campo há uma distribuição populacional geográfica dispersa e não aglomerada, no qual uma casa fica bem distante da outra, onde forma pequenas comunidades. Sendo assim, o transporte escolar deve ser uma assistência educacional que melhore as condições de deslocamento dos estudantes, viabilizado pelo deslocamento intracampo. Todavia, muitos dos governantes municipais ao longo do tempo, constantemente, viabilizam o transporte escolar no campo com o objetivo de diminuir custos com a manutenção de escolas nas comunidades rurais, assim utiliza o transporte escolar para o deslocamento em grandes percursos entre comunidades que geograficamente e culturalmente são díspares, e para agravar 
a situação há predominantemente o deslocamento campo/cidade, distanciando as crianças, jovens e adultos de sua cultura e do seu modo de viver no e do campo.

A forma de acessar a escola para muitos estudantes só foi possível com o transporte escolar, quando não se tinha políticas públicas que possibilitavam o acesso a esse direito, muitas crianças e jovens percorriam distâncias enormes para chegar à escola e muitos não tinham nem essa possibilidade (sabemos que ainda hoje essa realidade existe), pois em muitos casos o deslocamento era inviável devido à enorme distância em relação à residência do estudante até a escola. Os educandos do campo ficavam à mercê da boa votante dos governantes municipais.

Com a alteração da Lei n. ${ }^{\circ}$ 9.394/96, pelo acréscimo do inciso VII, no Art. 10, e do inciso VI, no Art. 11, por meio da Lei n 10.709, de 31 de julho de 2003, os Governos dos Estados e dos Municípios passaram a ser responsáveis pela garantia do transporte escolar para estudantes. Essa descentralização corrobora para o fechamento de escolas do campo, tendo em vista a redução de responsabilidades do Governo Federal, preceito que tem ratificação também na Lei $n^{\circ} 11.947$, de 16 de junho de 2009, no qual dispõem do atendimento da alimentação escolar e do Programa Dinheiro Direto na Escola aos alunos da Educação Básica.

O Brasil ao seguir as diretrizes neoliberais, de redução de investimentos e financiamentos dos setores públicos (saúde, educação, previdência, e outros) redefini e/ou cria políticas como a do transporte escolar, que por dentro dessa lógica torna-se mais viável, economicamente, do que manter uma escola funcionando. Ao fechar uma escola o Estado diminui custos com equipamentos escolares, funcionários e professores. Assim, para minimizar os custos e maximizar os investimentos em setores de maior competitividade de mercado, especialmente aqueles externos ao pais, inúmeras camadas sociais são prejudicadas. Como exemplo, viemos constatando, que milhares de crianças são transportadas para as cidades e/ou para outras comunidades muito distantes em ônibus e/ou outros veículos precários, sem nenhuma segurança, realidade que evidencia o predomínio do ideário neoliberal desse empresariamento da 
educação, em que a diminuição de custos é mais importante do que atender as necessidades da população. A lógica do custo-benefício nas políticas são fatores que contribuem para que o transporte escolar se transforme em uma política de esvaziamento do campo.

Apesar de um conjunto de legislações a negligência com as escolas ainda é significante no Brasil. Além do que acima foi colocado, outros exemplos de desqualificação do ensino para o população do campo estão na falta de infraestrutura física e pedagógica das escolas, nas condições precárias de trabalho do professor, na falta de formação destes à nível superior e de pós graduação. São estes, dentre tantos outros exemplos, que evidenciam o quando é negado o direito de desenvolver um processo educacional de trabalho no campo, de reafirmação, valoração e ampliação das identidades dos sujeitos do campo, neste país.

De acordo com Hage (2008), o processo de nucleação de escolas no Brasil tem vinculação direta com a política de transporte escolar, o autor afirma que na maioria das vezes as escolas fechadas no campo são as multisseriadas, que em grande parte são consideradas escolas isoladas em decorrência das grandes distâncias existentes entre a sede dos municípios e/ou distritos.

As Escolas multisseriadas do campo são marcadas pela heterogeneidade de sujeitos, os quais possuem idades próprias, níveis de conhecimentos, culturas, etc., essas diversidades devem ser reconhecidas e legitimadas nas políticas e práticas educativas. Hage (2014) afirma que as escolas multisseriadas geralmente se constituem como a única alternativa para os sujeitos estudarem nas suas comunidades rurais. Porém, a realidade, na qual muitas escolas encontram-se não favorece o sucesso e a continuidade nos estudos, pois a maioria está em situação precária e de abandono, muitas funcionam em prédios depauperados, sem ventilação, sem banheiros e local para armazenamento e confecção da merenda escolar, com carteiras insuficientes, quadro de giz danificado e outros. Sem contar que muitos professores são submetidos a grande rotatividade (de uma escola para outra), devido à punição por não fazer parte do grupo político que está no poder governamental do município. 
A simples abdicação e negação das escolas multisseriadas não resolverá os problemas que assolam as escolas do campo no Brasil. Esse discurso esconde a objetivação da eliminação de um espaço social importantíssimo que existe em muitas comunidades do campo.

A multisseriação sendo implementada num contexto de necessidade ou não, deve avançar em busca de alternativas para a integralidade da formação humana. Para Hage (2008) as escolas multisseriadas devem sair do anonimato das Secretarias Estaduais e Municipais de Educação, do Ministério da Educação, das universidades, sair da concepção urbano-cêntrica de mundo, no qual afirma que a vida escolar na cidade oferece o acesso a todos os bens e serviços públicos.

Essa premissa da nucleação, que é um ideário neoliberal, tem levado ao processo de fechamento das escolas do campo, sob a lógica do custo/benefício, da meritocracia competitiva. Dispositivos legais sobre a nucleação estão presentes na Resolução $n^{\circ} 2$, de 28 de abril de 2008, no qual esse processo é visto como uma alternativa e não como uma finalidade.

A nucleação notavelmente tem sido adotada, na Educação Escolar Infantil e Fundamental em muitos municípios, sob o argumento financeiro de redução dos custos de manutenção de uma escola e como alternativa à superação da multisserie e "consequentemente a melhoria na qualidade de ensino". Essas ações têm infringido a Resolução $\mathrm{n}^{\circ}$ 2, de 28 de abril de 2008, no qual em seu Art. $3^{\circ}$ estabelece que: "A Educação Infantil e os anos iniciais do Ensino Fundamental serão sempre oferecidos nas próprias comunidades rurais, evitando-se os processos de nucleação de escolas e de deslocamento das crianças" (BRASIL, 2008).

Entretanto, como em toda lei existe de certa forma brechas, os governantes municipais têm se apegado a existência da possibilidade do fechamento de escolas, por exemplo, o $\S 1^{\circ}$ do Art. $3^{\circ}$, ao dizer que os cincos anos iniciais do ensino fundamental, excepcionalmente, poderão ser oferecidos em escolas nucleadas, mas o deslocamento deve ser intracampo.

A que se fazer uma crítica, quanto à distância que os estudantes deverão percorrer no deslocamento de casa para a escola. Não há na diretriz uma 
especificação concreta da distância, dizer que deverá ser considerado o menor tempo possível a pé e/ou pela adoção do transporte, dá margem para diversas interpretações, conforme os interesses logísticos e financeiros dos municípios. Sendo necessária uma ampla articulação das comunidades para impedir as disparidades existentes nessas ações.

Por isso, faz-se necessário entender que "os fatos podem ser racionalmente compreendidos a partir do lugar que ocupam na totalidade do próprio real e das relações que se estabelecem com os outros fatos e com o todo" (KUENZER, 2008, p. 64), algo essencial para entendermos que o fechamento das escolas do campo faz parte de uma realidade capitalista totalizadora, que prima pela manutenção e ampliação da propriedade privada e do agronegócio.

\section{A realidade brasileira em relação ao fechamento de escolas do campo}

As diretrizes neoliberais estão inseridas nas políticas educacionais como uma forma de legitimar a exclusão da população e o esvaziamento do campo brasileiro. A descentralização e transferência de responsabilidade para os municípios, a privatização das escolas públicas. O intensivo processo de nucleação de escolas aprofunda ainda mais a exclusão ao negar o acesso à escola pública à maioria dos sujeitos.

Os pressupostos estabelecidos na Constituição Federal de 1988, pelo artigo 205 e pelo artigo 206 que dispõe sobre os princípios legais do acesso e permanência na escola estão sendo negados como um meio de consolidação do projeto de esvaziamento do campo. Mas como fazer para que esses objetivos e princípios garantidos por leis sejam efetivamente implementados? Apesar de leis e normativos legais que reconhece a educação do campo ainda persistem as ações de fechamento de escolas. Essa lógica neoliberal fica evidente aos observarmos o quadro $\mathrm{n}^{\circ} 01$, quando nos deparamos com os dados sobre as escolas no Brasil. 
Quadro n 1 - Número de Escolas Públicas no Brasil no período de 1995 a 2014.

\begin{tabular}{|l|l|l|}
\hline ANO & URBANA & RURAL \\
\hline 1995 & 63793 & 136825 \\
\hline 1996 & 61031 & 139923 \\
\hline 1997 & 63310 & 136518 \\
\hline 1998 & 64048 & 124418 \\
\hline 1999 & 68680 & 118942 \\
\hline 2000 & 70481 & 116371 \\
\hline 2001 & 72079 & 112521 \\
\hline 2002 & 73253 & 106480 \\
\hline 2003 & 74352 & 102322 \\
\hline 2004 & 75210 & 99482 \\
\hline 2005 & 75783 & 95728 \\
\hline 2006 & 76839 & 91391 \\
\hline 2007 & 77949 & 87720 \\
\hline 2008 & 79205 & 86104 \\
\hline 2009 & 79984 & 82647 \\
\hline 2010 & 80579 & 79027 \\
\hline 2011 & 81258 & 75828 \\
\hline 2012 & 81910 & 73666 \\
\hline 2013 & 82432 & 70260 \\
\hline 2014 & 82957 & 66919 \\
\hline
\end{tabular}

Fonte: PEREIRA, C. C. $(2016)^{1}$

Os dados apresentados (quadro 1) evidenciam um intenso fechamento de escolas no Brasil. É possível perceber que no ano de 1995 eram 136.825 escolas ativas no campo, mas no ano de 2014 tinham apenas 66.919 escolas ativas, uma diminuição de 69.906 mil escolas (PEREIRA, 2017). Destacamos que não encontramos estatísticas nos anos posteriores a 2014 sobre o número de escolas públicas, impossibilitando-nos novas análises. Mas, por meio desses dados temos a possibilidade de entender que as ações de fechamento de escolas coadunam com um governo neoliberal, no qual age de maneira a destituir o direito de ter uma escola pública por parte da classe trabalhadora.

A migração das famílias para a cidade em busca de trabalho e educação tem intensificado o fechamento de escolas do campo, assim como também a degradação das condições de vida dos sujeitos que vivem no/do campo, algo que resulta no fortalecimento de uma concepção neoliberal. Ao analisarmos o contexto de escolas localizadas no espaço urbano verificamos que também há

1Dados organizados por Camila Casteliano Pereira (2016), em sua dissertação de mestrado intitulada "A Política de Fechamento de Escolas no Campo na Região Metropolitana de Curitiba". 
redução de escolas públicas, mas essa situação ocorre mais precisamente nas periferias, onde mora a classe trabalhadora, população desprivilegiada de direitos sociais e econômicos. Materializa-se assim um problema de retirada da possibilidade de escolarização da classe trabalhadora em geral.

Nesse contexto, marcado pela negação de direitos, pela intensificação do fechamento de escolas, os movimentos sociais, organizações e lideranças de diversos seguimentos sociais, em especial o Movimento dos Trabalhadores Rurais Sem Terra (MST), denunciaram o intenso fechamento das escolas do campo, ao divulgar os dados e alertar sobre a necessidade de impedir 0 fechamento de escolas.

A partir do I Encontro de Educadores e Educadoras da Reforma Agrária (ENERA) e das Conferências houve uma discussão mais ampla e coletiva sobre o fechamento de escolas do campo, e com a ampliação dessa retirada de direitos o MST organiza uma campanha no ano de 2011, intitulada "Fechar Escola é Crime" (figura 1). Através dessa campanha teve uma maior visibilidade nacional em relação a essa realidade. A campanha teve o intuito de denunciar 0 fechamento de escolas do campo e esclarecer/debater sobre os desafios ao acesso à escola, melhoria das condições físicas/pedagógicas, e à organização da educação nos acampamentos e assentamentos das áreas de reforma agrária, agricultura familiar e camponesa, assim como também, ampliar a discussão sobre a importância de mobilização das comunidades, movimentos sociais, sindicatos, toda a classe trabalhadora na busca de mudança da realidade política e social do campo no Brasil (MST, 2011).

Segundo o MST (2011) mais de 24 mil escolas do campo foram fechadas entre 2002 e 2010. Com o fechamento de escolas o direito a educação está sendo negado a milhares de crianças, jovens e adultos que moram no campo. 
Figura n 1 - Cartaz da campanha do MST "Fechar escola é crime", 2011.

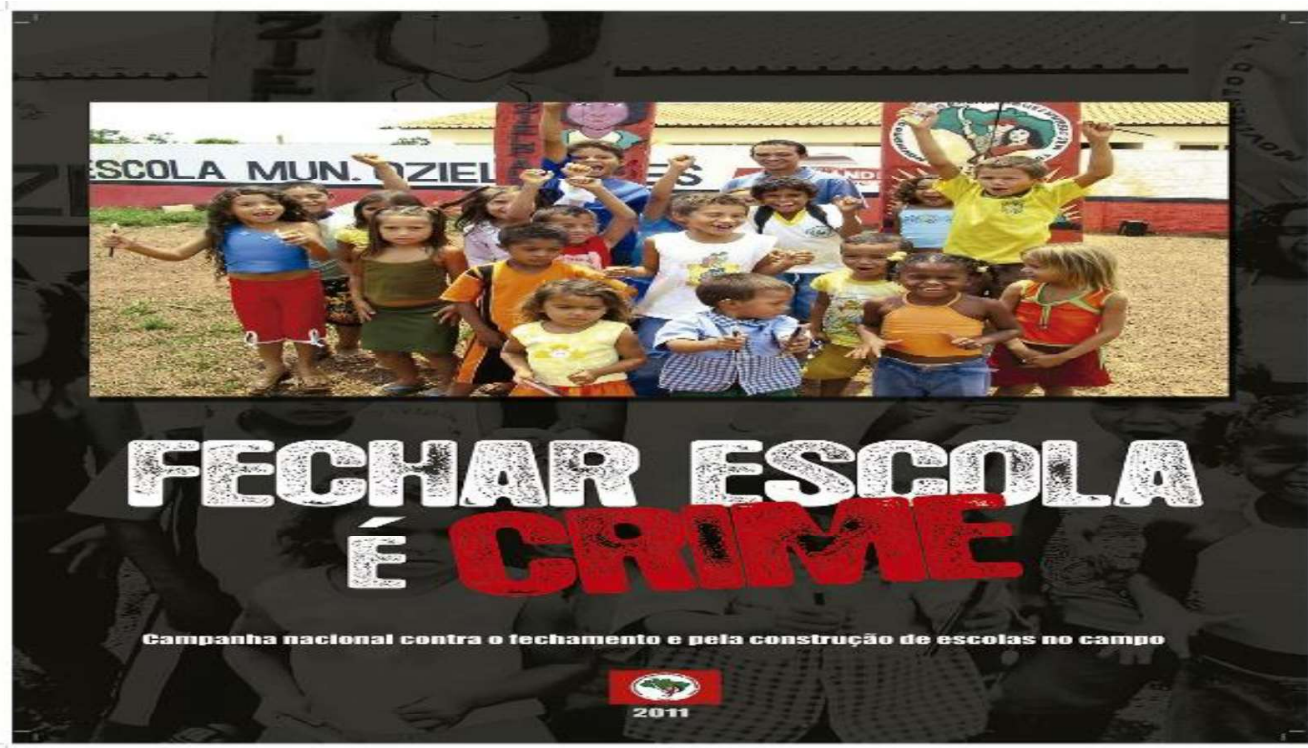

Fonte: MST. (2011).

O processo de fechamento de escolas, intensificado com a nucleação tende a reduzir o número de comunidades do campo, pois muitos pais acabam mudando para distritos ou cidades para acompanharem seus filhos, que acabam sofrendo preconceito por parte dos alunos que moram no meio urbano, incorpora-se a esse preconceito a "desestruturação das comunidades rurais, feita através da escola, aos acidentes devido à precariedade dos transportes e das estradas, as longas viagens de ida e volta, cujo cansaço de professores e alunos interferem na aprendizagem" (RIBEIRO, 2013, p. 183).

O MST (2011) ao apresentar os dados do Censo Escolar do INEP/MEC (2002 a 2009) afirma que a realidade da educação brasileira é ainda precária, com 14,1 milhões de analfabetos, sendo que um em cada cinco brasileiros é analfabeto funcional, e entre as pessoas com mais de 15 anos considerados analfabetos funcionais, mais de um terço vivem no Nordeste e, destas, mais da metade vivem no meio rural. A figura 2 vem ratificar essa análise, pois no ano de 2016 a taxa de analfabetismo das pessoas de 15 anos ou mais de idade era de $(7,2)$, quando há um aumento da idade observamos que a taxa de analfabetismo é ainda maior, ficando em $(7,7)$ para as pessoas de 18 anos ou mais, $(8,8) 25$ anos ou mais, $(12,3) 40$ anos ou mais, e $(20,4) 60$ anos ou mais. Se analisarmos 
a cor ou raça verificaremos que a maior taxa está entre os pretos e pardos, enquanto que em relação às regiões, a região Norte e Nordeste fica com um percentual maior de analfabetismo.

Figura $n^{\circ} 2-$ Taxa de analfabetismo das pessoas de 15 anos ou mais

de idade

no ano de 2016.

\section{Taxa de analfabetismo das pessoas de 15 anos} ou mais de idade

Região Nordeste

apresentou a maior taxa de analfabetisno, em torno de quatro vezes maior do que as taxas estimadas para o Sudeste e o Sul
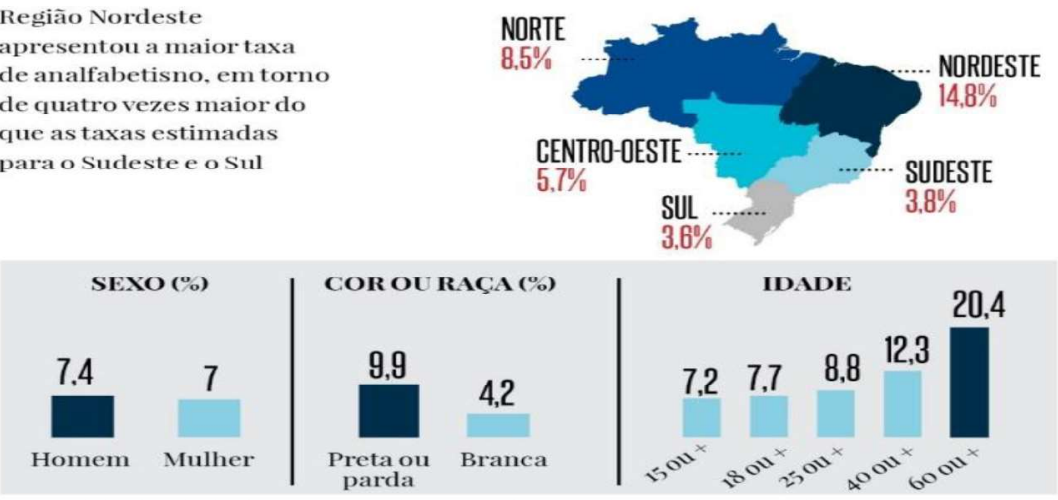

Fonte: IBGE, Diretoria de Pesquisas, Coordenação de Trabalho e Rendimento. Pesquisa Nacional por Amostra de Domicilios Contínua 2016

Fonte: www.revistaeducacao.com.br

Esses dados demonstram que o Brasil é materialização das políticas neoliberais, seja no campo ou na cidade, pois o que está nesse jogo estratégico é a imposição do sistema capitalista, se utilizando da exploração de uma classe para sua manutenção. A construção da política educacional nesta sociedade é organizada como manipulação para a perpetuação das relações hegemônicas de classe - inclusive ainda com base na "velha" e insistente burguesia.

Diversos são os fenômenos que têm desencadeado uma educação escolar precária, como pode ser observado nas discussões anteriores, e o fechamento das escolas do campo faz parte dessa estratégia, para implementar o modelo de desenvolvimento econômico capitalista baseado no agronegócio. Os dados veem corroborar com essa afirmação, pois segundo o Censo escolar do Instituto Nacional de Estudos e Pesquisas Educacionais Anísio Teixeira (INEP), no ano de 2014 foram 4.084 escolas fechadas no Brasil. O MST (2015) afirma que se analisarmos os últimos 15 anos, essa quantidade salta para mais 
de 37 mil unidades educacionais a menos no meio rural, como pode ser observado na figura a baixo:

Figura $n^{\circ} 3$ - Fechamento de escola do campo no Brasil, 2014.

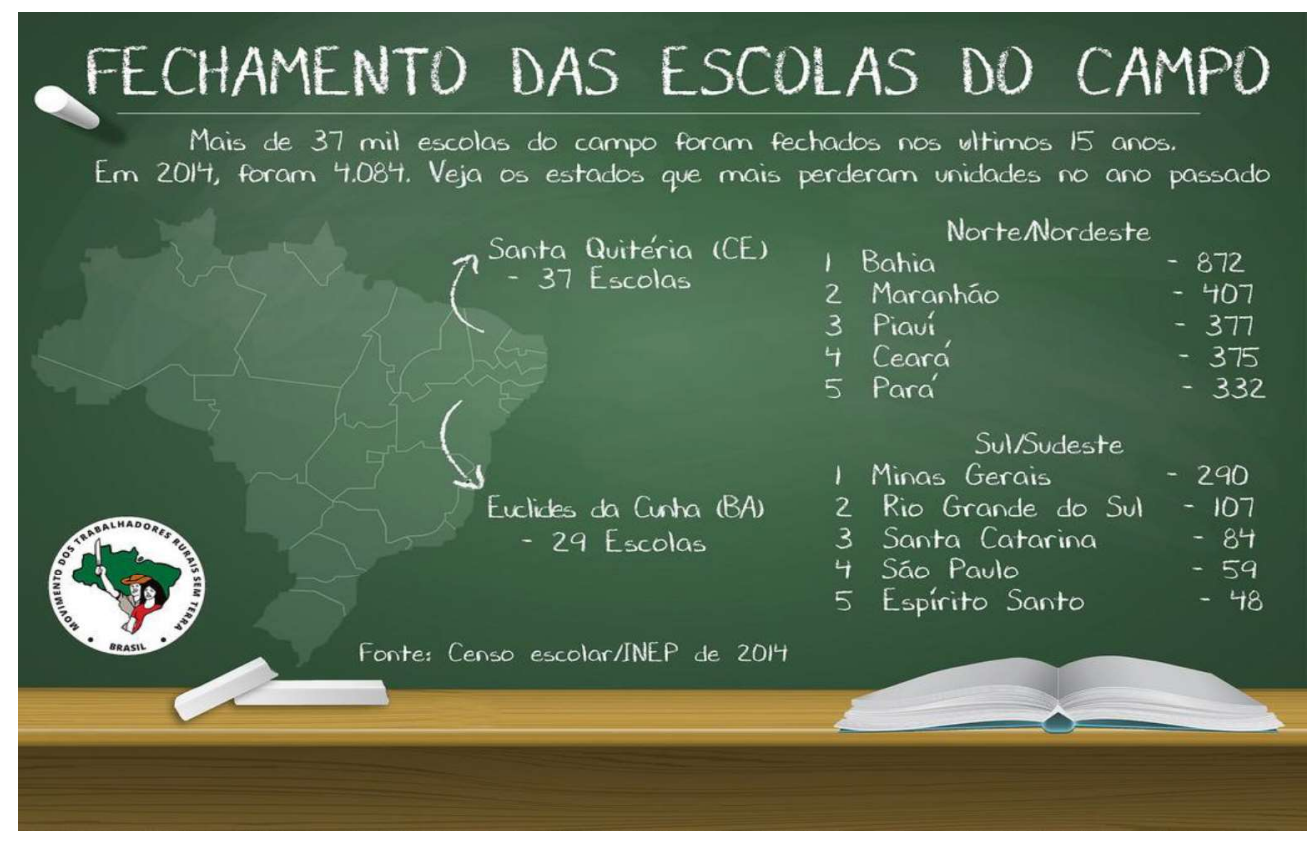

Fonte: MST (2015).

Segundo os dados do INEP, apresentados pelo MST (2015), a maioria das escolas fechadas pertence à rede municipal. Podemos observar na figura que dentre as regiões as que mais fecharam escolas no ano de 2014 foram à região Norte e Nordeste. Só no Estado da Bahia foram 872 escolas fechadas, seguido por Maranhão com 407 e Piauí com 377 escolas fechadas. O MST (2015) afirma que dentre as principais justificativas das prefeituras para o fechamento está à alegação de ter um número reduzido de alunos matriculados nas escolas do campo, sendo insuficiente economicamente para manter em funcionamento tais escolas.

Em relação ao número de matrículas identificamos, por meio das notas estatísticas do Censo Escolar de 2018 do INEP, que no referido ano, foram registradas 48,5 milhões de matrículas nas 181,9 mil escolas de educação básica, 1,3 milhão a menos em comparação com o ano de 2014, o que condiz com uma redução de 2,6\% no total de matrículas da educação básica no Brasil.

Percebe-se assim, um período de contradição, tendo em vista que, como mencionado no item 3.2, no ano de 2014 houve a aprovação do decreto 12.960/2014 que aumenta o nível de exigência para que uma escola do campo 
seja fechada, entretanto na prática essa exigência não se efetivou. Pesquisas evidenciam que um grande número de escolas tem sido fechadas no Brasil sem o consentimento da comunidade e dos Conselhos Municipais de Educação, infringindo a lei. Este problema tende a se acentuar por conta de política de cortes orçamentários e diretrizes neoliberais que o atual governo burguês do Brasil adotou. Há no país uma falsa democratização que esconde a verdadeira faceta mercadológica na área da educação pública.

Reis e Moreno (2015) ao realizarem um trabalho intitulado "Brasil urbano x Brasil rural" apresenta um país marcado pela exclusão e segregação da população camponesa, no que se refere a educação escolar pública do Brasil. Apresentam os dados do Censo Escolar 2014 (Inep), tabulados, segundo os autores, a pedido do G1 pela Fundação Lemann e pela Meritt, responsáveis pelo portal QEdu. Em relação à infraestrutura, os autores afirmam que (70\%) das escolas urbanas contam com esgoto encanado, enquanto que apenas (5\%) das escolas do campo tem acesso a esse serviço, sendo que $(80 \%)$ das escolas rurais dependem de fossas e (15\%) não contêm nenhum tipo de estrutura para os resíduos. Em relação à água encanada (94\%) das escolas urbanas possuem conexão com uma rede de água, e (27\%) das escolas do campo contam com a ligação. Apenas (13\%) das escolas do campo conta com uma biblioteca e (16\%) têm acesso à rede mundial de computadores.

A questão da política pública educacional abarca o debate das contradições presentes na sociedade. Contradição explícita no questionamento de Caldart (2012, p. 263): "Como pensar em políticas de educação no campo ao mesmo tempo em que se projeta um campo com cada vez menos gente?". A todo momento o Estado descumpre os direitos historicamente conquistados, mantendo ações de expropriação da terra, de fechamento de escolas, etc. com políticas públicas acompanhadas por uma natureza contraditória, que não articula trabalho e educação em um sentido amplo para a vida.

Devemos ter a clareza, como bem explica Vendramini (2015), que o futuro das escolas do campo está relacionado de modo direto ao futuro do campo. A saída da população do campo implica uma maior vulnerabilidade das escolas situadas em comunidades rurais. Realidade que vem sendo constatada pelos 
dados aqui apresentados, e até mesmo em forma de denúncias ao desrespeito ao sujeito do campo, por estudos e pesquisas dessa temática, especialmente a partir da primeira década dos anos 2000.

A educação do campo historicamente recebeu pouca atenção nas agendas governamentais em termos de políticas públicas específicas para a formação de educadores e educandos do campo, situação que provoca profundos problemas na escolarização das crianças, jovens e adultos que tem o seu futuro educacional escolar ameaçado. Afinal, o Estado atende de forma mínima demandas da classe trabalhadora e faz muitas concessões a favor do capital, como exemplo aos empresários do agronegócio. E como falsa solução são fomentados programas compensatórios e assistencialistas, que não são criados com a finalidade de permanência no campo. Dessa forma, a população do campo acaba migrando para as cidades em busca de continuação da formação educacional e à procura de emprego. Entretanto, sabemos que, grande parte dos migrantes, expulsos de suas terras, acabam indo para as favelas e periferias das cidades, tornando-se mão de obra assalariada para os grandes proprietários dos meios de produção (VENDRAMINI, 2015).

Marçal Ribeiro (1993) nos esclarece que a história mostra que a educação escolar no Brasil nunca foi considerada uma prioridade. A educação no país foi, ao longo dos tempos, constituída para servir unicamente a uma determinada classe social e desfavorecer a classe trabalhadora que permanece iletrada e sem acesso à escola. Nas palavras do autor, mesmo passando de uma economia agrária-comercial-exportadora para uma economia com base industrial e tecnológica, mesmo com as mudanças políticas, o Brasil não priorizou a educação formal, assim a educação, advindas dos processos de correlações de forças, teve seu desenvolvimento intimamente associada a transmissão da ideologia das elites, atendendo apenas a burguesia.

Em decorrência dessa lógica de manutenção do poder para uma pequena parcela da sociedade, as escolas do campo no Brasil enfrentam problemas de infraestrutura, adequação de conteúdos e formação inadequada dos professores à realidade dos sujeitos do campo, que historicamente apresentam menores 
níveis de escolarização, maiores níveis de reprovação, abandono, defasagem idade-série e analfabetismo (VENDRAMIN, 2015).

Quadro $n^{\circ} 2$ - Pessoas de 10 anos ou mais de idade, totais e alfabetizadas, por situação do domicílio, segundo as Grandes Regiões e as Unidades da Federação - 2010.

\begin{tabular}{|c|c|c|c|c|c|c|}
\hline $\begin{array}{l}\text { Grandes } \\
\text { Regiões } \\
\text { e } \\
\text { Unidade } \\
\text { s da } \\
\text { Federaç } \\
\text { ão }\end{array}$ & $\begin{array}{l}\text { Pessoas de } \\
10 \text { anos ou } \\
\text { mais } \\
\text { Total }\end{array}$ & $\begin{array}{l}\text { Pessoas } \\
\text { de } 10 \text { anos } \\
\text { ou mais } \\
\text { Urbana }\end{array}$ & \begin{tabular}{ll}
\multicolumn{2}{l}{ Pessoas } \\
de $\quad 10$ \\
anos & ou \\
mais & \\
Rural &
\end{tabular} & $\begin{array}{l}\text { Pessoas } \\
\text { de } 10 \text { anos } \\
\text { ou mais } \\
\text { Alfabetiza } \\
\text { das } \\
\text { Total }\end{array}$ & $\begin{array}{l}\text { Pessoas } \\
\text { de } 10 \text { anos } \\
\text { ou mais } \\
\text { Alfabetiza } \\
\text { das } \\
\text { Urbana }\end{array}$ & $\begin{array}{l}\text { Pessoas } \\
\text { de } 10 \\
\text { anos ou } \\
\text { mais } \\
\text { Alfabetiza } \\
\text { das } \\
\text { Rural }\end{array}$ \\
\hline Brasil & $\begin{array}{l}161.990 .26 \\
5\end{array}$ & $\begin{array}{l}137.489 .3 \\
61\end{array}$ & $\begin{array}{l}24.500 .9 \\
04\end{array}$ & $\begin{array}{l}147.378 .1 \\
82\end{array}$ & $\begin{array}{l}128.084 .9 \\
03\end{array}$ & $\begin{array}{l}19.293 .27 \\
9\end{array}$ \\
\hline $\begin{array}{l}\text { Região } \\
\text { Norte }\end{array}$ & 12.670 .041 & 9.464 .858 & $\begin{array}{l}3.205 .18 \\
3\end{array}$ & $\begin{array}{l}11.326 .49 \\
2\end{array}$ & 8.762 .713 & 2.563 .779 \\
\hline $\begin{array}{l}\text { Região } \\
\text { Nordest } \\
\mathrm{e}\end{array}$ & 44.223 .349 & $\begin{array}{l}32.629 .99 \\
0\end{array}$ & $\begin{array}{l}11.593 .3 \\
59\end{array}$ & $\begin{array}{l}36.418 .12 \\
4\end{array}$ & $\begin{array}{l}28.276 .92 \\
5\end{array}$ & 8.141 .199 \\
\hline $\begin{array}{l}\text { Região } \\
\text { Sudeste }\end{array}$ & 69.532 .602 & $\begin{array}{l}64.706 .19 \\
9\end{array}$ & $\begin{array}{l}4.826 .40 \\
3\end{array}$ & $\begin{array}{l}65.979 .57 \\
8\end{array}$ & $\begin{array}{l}61.798 .92 \\
8\end{array}$ & 4.180 .650 \\
\hline $\begin{array}{l}\text { Região } \\
\text { Sul }\end{array}$ & 23.694 .211 & $\begin{array}{l}20.125 .47 \\
8\end{array}$ & $\begin{array}{l}3.568 .73 \\
3\end{array}$ & $\begin{array}{l}22.571 .64 \\
1\end{array}$ & $\begin{array}{l}19.297 .02 \\
8\end{array}$ & 3.274 .613 \\
\hline $\begin{array}{l}\text { Região } \\
\text { Centro- } \\
\text { Oeste }\end{array}$ & 11.870 .062 & $\begin{array}{l}10.562 .83 \\
6\end{array}$ & $\begin{array}{l}1.307 .22 \\
6\end{array}$ & $\begin{array}{l}11.082 .34 \\
7\end{array}$ & 9.949 .309 & 1.133 .038 \\
\hline
\end{tabular}

Fonte: Elaborado pelas autoras com base no IBGE, Censo Demográfico 2010.

As estatísticas apresentadas no quadro $n^{\circ} 4$ demonstram 0 índice de pessoas alfabetizadas com idade de 10 anos ou mais de idade, por situação de domicílio, distribuídas nas grandes regiões do país e unidades da federação, conforme pesquisa do IBGE, através do censo demográfico (2010), no qual verificamos que no Brasil, temos uma grande população composta de 161.990.265 habitantes, com faixa etária a partir de 10 anos de idade ou mais no país, e que dessa totalidade, 137,489,361 residem no espaço urbano enquanto que, apenas 24,500,904, estão localizados no meio rural. Ao refletir sobre a população alfabetizada nesses mesmos espaços, observa-se que o maior número de letrados ocupa o espaço urbano, sendo ao todo 128,084,93 de um total de 147,378,182 da população alfabetizada. Já no meio rural esse índice é bem reduzido apenas 19.293,279, desse montante da população com 10 anos de idade ou acima dessa faixa etária estão alfabetizados. As regiões do Brasil evidenciam outras disparidades numéricas, em meio a população alfabetizada 
entre as regiões do país, a região sudeste e a que se apresenta de forma confortável, de acordo a totalidade da sua população alfabetizada, com 69,532,692 habitantes e dessa número populacional 65,979,578 ocupa o espaço urbano e desse montante $61,798,928$ estão alfabetizados nessa faixa etária. Diferentemente do espaço urbano o meio rural nessa região apresenta uma pequena população rural, cerca de 4,826,403 habitam nesse espaço e desse total $4,180,650$ dessa população encontra-se alfabetizada nessa mesma faixa etária.

A região mais crítica apresentada é a Nordeste, considerada a segunda maior do país, com um em índice populacional de 44,223,149 habitantes distribuídos entre os espaços rurais e urbanos. Desse total 28,276,925 localizam na zona urbana e foram alfabetizados com 10 anos de idade ou mais, enquanto que no espaço rural dos 11,593,359 são moradores do meio rural e desse total apenas 8,141,199 conseguiram alfabetizar-se nessa idade. Um índice muito alto de analfabetismo nessa região, ainda é perceptível, se comparado a outras regiões do país.

Outro dado que mostra a falta de compromisso com a população do campo é revelado pelo Censo Escolar do INEP, no qual constatou que no ano de 2016 o Brasil contava com 186,1 mil escolas de educação básica, no de 2017 passou para 184, 1 mil escolas, novamente houve uma redução do número de escolas, passando para 181,9 mil escolas no ano de 2018. Nas notas estatísticas do Censo escolar do INEP do ano de 2016, observamos que $(33,9 \%)$ das escolas brasileiras encontravam-se no campo e $(66,1 \%)$ no meio urbano. Em 2017 , observa-se que houve um aumento das escolas urbanas, passando para (67, $0 \%$ ) e uma diminuição de $(0,9 \%)$ nas escolas do campo. Algo que também merece ser destacado é a participação das escolas da rede privada no ano de 2017, que passou de (21,1\%) em 2015 para (21,5\%) em 2016, (21,7\%) em 2017 e $(22,3 \%)$ no ano de 2018.

Em relação ao Ensino Médio (89,7\%) das escolas estão no meio urbano e apenas (10,3\%) no campo, é a menor participação do meio rural em toda a educação básica. Com esses dados não estamos dizendo que os estudantes do meio urbano não precisa ser assistido, mas evidenciamos que os educandos do 
campo também querem estudar e tem direito de estudar, por isso as escolas devem existir tanto na cidade quanto no campo, de forma que inexista essa disparidade do Ensino Médio entre os locais, uma vez que os sujeitos do campo também tem o direito de continuarem seus estudos, passar pela educação básica e posteriormente se inserirem em algum curso superior que seja de sua vontade.

Ainda referindo-se ao censo escolar 2017 verificamos que $(10,8 \%)$ das matrículas da educação infantil estão em escolas do campo e apenas (4,5\%) das matrículas do ensino médio estão nas escolas do campo. Uma diferença significativa quando se compara com as matrículas no meio urbano, revelando a invisibilidade da infância no meio rural.

Assim, percebemos que a educação que deveria ser prioritária perde lugar para o capital que está sempre assumindo posição de destaque quando se trata da utilização dos recursos públicos. Os traços de nossa colonização não foram superados, há ainda aspectos de uma sociedade latifundiária, escravocrata, elitista, preconceituosa e seletiva, que sustentada por uma economia capitalista, reafirma a não necessidade de ter uma classe trabalhadora crítica, com um diploma, uma formação superior que lhe possibilite o entendimento da realidade concreta, mas sim ter um exército de reserva disponível e submissa à ordem capitalista.

\section{Considerações finais}

Os programas governamentais direcionados para a população do campo e para as escolas do campo seguem a lógica do capital neoliberal, assim, desde os primeiros registros históricos sobre esse assunto sempre houve poucos recursos econômicos para as escolas localizadas no meio rural.

Em um primeiro momento a educação estava voltada a fixar o homem no campo para conter a concentração de pobreza e violência nas cidades e atualmente há o interesse de retirar o homem do campo com o agrupamento de alunos em uma escola considerada de porte físico maior, através da nucleação e/ou fechamento de escolas consideradas isoladas e com poucos alunos, mas sabemos que desde o século XX a escolarização no campo foi implementada no 
sentido de priorizar os interesses dos detentores do poder econômico capitalista, fato que conduz a população do campo ao analfabetismo e para a falta de perspectiva de trabalho e continuidade dos estudos em escolas do campo.

Diante do quadro atual da educação e do fechamento de escolas compreendemos que ter um posicionamento crítico e pautado em novas alternativas, possibilidades e projetos sócio-politicos, perante esses fatos e acontecimentos históricos é parte fundamental para outra construção social.

O fechamento das escolas no campo interfere na formação dos sujeitos, pois privados do acesso aos conhecimentos (científicos, tecnológicos e culturais) que foram transformados e sistematizados ao longo do tempo, a classe trabalhadora terá mais dificuldades de encontrar os caminhos para a transformação e efetivação das políticas educacionais. Sendo assim, não podemos lutar somente pela manutenção da escola do campo, mas pelas condições adequadas de infraestrutura, apoio logístico, materiais didáticos, formação de professores, etc. Os fatos e fenômenos abordados na escola não podem ser considerados fora de um contexto histórico, social, político, cultural e econômico.

O fechamento de escolas do campo está baseado em um projeto de sociedade da e para a classe dominante. Portanto, a escola do campo demanda ser um espaço de contraposição ao ideário neoliberal capitalista e de abertura para novas e diferentes estruturas e concepções de ensino e formação humana, com objetivos claros de fortalecer a relação harmoniosa dos sujeitos com a Terra, como lugar de produção e Vida.

\section{Referências}

BRASIL. Constituição da República Federativa do Brasil de 1988. Brasília, DF: Senado Federal, 1988.

. Lei $n^{\circ}$ 9.394, de 20 de dezembro de 1996. Estabelece as diretrizes e bases da educação nacional. Diário Oficial da União, Brasília, DF, 23 dez. 1996.

. Ministério de Educação. Resolução CNE/CEB n 01, de 03 de Abril de 2002. Institui Diretrizes Operacionais para a Educação Básica nas Escolas do Campo. Diário Oficial da União, Brasília, 9 de abril de 2002. Seção 1, p. 32 
. Ministério de Educação. Resolução CNE/CEB n 3, de 9 de julho de 2008. Dispõe sobre a instituição e implantação do Catálogo Nacional de Cursos Técnicos de Nível Médio. Diário Oficial da União, Brasília, 10 de julho de 2008, Seção 1, p. 9.

Ministério de Educação. Resolução CNE/CEB n 5, de 22 de junho de 2012. Define Diretrizes Curriculares Nacionais para a Educação Escolar Indígena na Educação Básica. Diário Oficial da União, Brasília, 25 de junho de 2012, Seção 1, p. 7.

. Estatuto da Criança e do Adolescente, Câmera dos Deputados, Lei no 8.069, de 13 de julho de 1990. DOU de 16 de julho de 1990 - ECA. Brasília, DF.

Lei $\mathbf{n}^{\circ} \mathbf{1 2 . 9 6 0}$, de 27 de março de 2014. Altera a Lei no 9.394, de 20 de dezembro de 1996. Brasília, 2014. Disponível em: <http://www.planalto.gov. br/ccivil_03/_ato2011-2014/lei/112960.htm>. Acesso em 18 ago. 2017.

. Ministério da Educação. Parecer CNE/ CEB no 23/2007, de 12 de setembro de 2007. Disponível em: <http://portal.mec.gov.br/cne/arquivos/pdf/2007/pceb023_07.pdf>. Acesso em: 29 de ago. de 2018.

CALDART, Roseli Salete. Educação do Campo. In: CALDART, Roseli S. et al. (Org.). Dicionário da Educação do Campo. Rio de Janeiro; São Paulo: Escola Politécnica de Saúde Joaquim Venâncio, Expressão Popular, 2012, p. 259-267.

HAGE, Salomão A. M. Transgressão do paradigma da (multi)seriação como referência para a construção da escola pública do campo. Educ. Soc., Campinas, v. 35, nº 129, p. 1165-1182, Out. Dez., 2014.

A multissérie em pauta: para transgredir o paradigma seriado nas escolas do campo. Belém: Geperuaz, 2008.

IBGE. Censo Demográfico, 2010. Disponível em: www.ibge.gov.brDisponível em: https://censo2010.ibge.gov.br/sinopse/index.php?uf=29\&dados=10. Acesso em 01 de ago. de 2018.

INEP. Instituto Nacional de Estudos e Pesquisas Educacionais Anísio Teixeira. Sinopse Estatística da Educação Básica. Brasília: Inep, 2018. Disponível em: http://inep.gov.br/ sinopses-estatisticas-da-educacao-basica. Acesso em: 24.08.2018.

KUENZER, Acácia, Z. Desafios teórico-metodológicos da relação trabalhoeducação e o papel social da escola. In: FRIGOTTO, Gaudêncio (org.). Educação e crise do trabalho: Perspectivas de final de século. 9 ed. Petrópolis, RJ: Vozes, 2008.

MARÇAL RIBEIRO. Paulo R. História da educação escolar no Brasil: notas para uma reflexão. Paidéia (Ribeirão Preto) [online]. 1993, n.4, p.15-30. Disponível em:

https://www.scielo.br/scielo.php?pid=S0103- 
$863 \times 1993000100003 \&$ script=sci_abstract\&tlng=pt. Acesso em: 24 de mai. de 2020.

MST. Movimento dos Trabalhadores Sem Terra. Mais de 4 mil escolas do campo fecham suas portas em 2014. 2015. Disponível em: http://www.mst.org.br/2015/06/24/mais-de-4mil-escolas-do-campo-fechamsuas-portas-em-2014.html. Acesso em: 12 de jul. de 2020.

Fechar escola é crime! 2011. Disponível em: <http://www.mst.org.br/2011/05/31 fechar-escola-e-crime.html> Acesso em: 06 de jun. de 2020.

PEREIRA, Camila Casteliano. A Política de Fechamento de Escolas no Campo na Região Metropolitana de Curitiba. Curitiba, UTP, 2017. (Dissertação de Mestrado em Educação).

REIS, Thiago; MORENO, Ana Carolina. Brasil urbano x Brasil rural. Disponível em:< http://especiais.g1.globo.com/educacao/2015/censo-escolar-2014/brasilurbano-x-brasil-rural.html>. Acesso em 01 de Jul. de 2020.

RIBEIRO, Marlene. Movimento Camponês, trabalho e educação: Liberdade, autonomia, emancipação: princípios/fins da formação humana. 2. ed. São Paulo Expressão Popular, 2013.

VENDRAMINI, Célia Regina. Qual o Futuro das Escolas no Campo? Educação em Revista, Belo Horizonte, v. 31, n. 03, p. 49-69, Jul./Set., 2015.

\section{Sobre os Autores}

\section{Vanessa Costa dos Santos}

vanessacosta792@gmail.com

Mestre em Ensino pelo Programa de Pós-Graduação em Ensino da Universidade Estadual do Sudoeste da Bahia - UESB (2019); Graduada em Geografia pela UESB (2016). Participa como Pesquisadora do Grupo de Estudos e Pesquisa em Educação do Campo (GEPEC) - CNPq - UESB e do Grupo de Estudos e Pesquisa em Movimentos Sociais, Diversidade, Educação do Campo e Cidade GEPEMDECC- CNPq - UESB. Desenvolve estudos e pesquisas em temáticas sobre o Neoliberalismo, Fechamento de escolas do campo, Políticas Públicas Educacionais, Educação do Campo e Movimentos Sociais.

\section{Fátima Moraes Garcia}

fatimamg2017@gmail.com

Professora titular da Universidade Estadual do Sudoeste da Bahia/UESB. Doutora em Educação, Cultura e Tecnologia pelo PPGE/UFPR e Pós-doutorado pelo PPGE/FACED/UFBA. Mestre em Ciência do Movimento Humano pelo PPGCMH/UFSM. Licenciada em Educação Física pela UFSM. Professora e Orientadora do Programa de Pós-Graduação em Ensino da UESB. Coordenadora do Grupo de Estudos e Pesquisa em Educação do Campo - 
GEPEC/CNPq/UESB. Desenvolve estudos e pesquisas em temáticas que tratam de Educação, Educação Física, Trabalho, Políticas Educacionais, Educação do Campo, Escola e Movimentos Sociais. 